\title{
Review
}

Zhou Wang*, Qing Liu, Haitao Liu, and Shizhong Wei

\section{A review of end-point carbon prediction for BOF steelmaking process}

https://doi.org/10.1515/htmp-2020-0098

received July 27, 2020; accepted October 08, 2020

\begin{abstract}
The precise prediction of end-point carbon content in liquid steel plays a critical role in increasing productivity as well as energy efficiency that can be achieved in the basic oxygen furnace (BOF) steelmaking process. Due to numerous and diversity of the studies on BOF end-point carbon prediction, it seems necessary to provide a comprehensive literature review on state-of-the-art developments in end-point carbon prediction for BOF steelmaking. This paper presents the characteristics of different end-point carbon prediction models. The endpoint carbon prediction for BOF steelmaking has initially relied on the experience and skill of the operators. With the development of information technology and autodetection methods, BOF end-point carbon prediction mainly has gone through three stages, such as static prediction, dynamic prediction, and intelligent prediction. Future contributions to the development and application of intelligent end-point carbon prediction in BOF steelmaking are still arduous tasks. However, it is envisaged that the intelligent end-point carbon prediction will witness more frequent applications and greatly improve the high-quality, highefficiency, and stable production for BOF steelmaking in the future.
\end{abstract}

\footnotetext{
* Corresponding author: Zhou Wang, School of Materials Science and Engineering, Henan University of Science and Technology, Luoyang 471023, Henan, China; Collaborative Innovation Center of Non-ferrous Metals, Henan Province, Henan University of Science and Technology, Luoyang 471023, Henan, China, e-mail: wangzhou29@163.com, tel: +86-0379-64-27-3071 Qing Liu: State Key Laboratory of Advanced Metallurgy, University of Science and Technology Beijing, Beijing 100083, China

Haitao Liu: School of Materials Science and Engineering, Henan University of Science and Technology, Luoyang 471023, Henan, China

Shizhong Wei: National Joint Engineering Research Centre for Abrasion Control and Molding of Metal Materials, Henan University of Science and Technology, Luoyang 471023, Henan, China
}

Keywords: BOF steelmaking, end-point carbon, intelligent prediction

\section{Introduction}

Basic oxygen furnace (BOF) steelmaking is the main method for the steelmaking process. According to statistical data, the crude steel produced by BOF accounts for $70.8 \%$ of the global steel production in 2018 [1]. As one of the key operations, precise prediction and control of endpoint carbon content in molten steel would greatly promote high-quality, high-efficiency, and stable production for the BOF steelmaking process [2-5].

Figure 1 illustrates the schematic representation of BOF steelmaking; a charge of hot metal and scrap is rapidly refined into the liquid steel with desired carbon content through the oxidation of supersonic oxygen injection from top lance and stirring of bottom gas from bottom tuyeres. Meanwhile, the fluxes such as lime and dolomite are added to the vessel to slag, and impurities were removed [6-8]. From a process control perspective, the decarburization of hot metal in BOF steelmaking is extremely complex since it takes place at high temperature and contains turbulent multiphase flow and chemical reactions. It is very difficult to monitor and collect data during the BOF steelmaking process due to the high temperature, aggressive chemical environment, and the violent motion of the mass [9]. The complicated interaction between various influential factors determines the endpoint carbon content in molten steel. Therefore, the accurate prediction and control of end-point carbon content in liquid steel is still a challenge for BOF steelmaking, especially for medium-high carbon steel smelting.

End-point carbon prediction with good generalization and high accuracy would certainly improve the productivity and steel quality that can be achieved in BOF steelmaking. Therefore, this paper presents a literature review on the characteristics of different end-point carbon prediction models and auto-detection methods in potential applications for BOF steelmaking. 


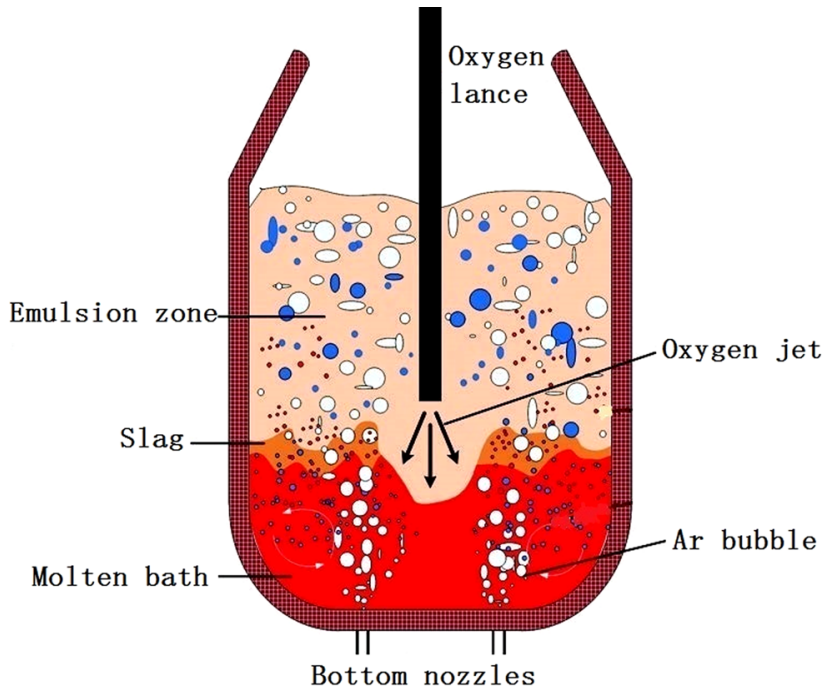

Figure 1: Schematic of BOF steelmaking. Adapted from ref. [7]. process. With the development of computer and information technology, the study on computer control of BOF steelmaking had been carried out in the early 1960s. In 1959, the static charge model based on computer calculation was first exploited by Jones \& Laughlin Steel Corporation, which was used to calculate the amount of charged hot metal, scrap, and slagging materials and guide endpoint carbon control of liquid steel [11,12]. Furthermore, with the rapid development of auto-detection methods, mathematical models, and algorithms, dynamic and intelligent end-point carbon predictions are available in the BOF steelmaking process. Based on the features of collected data, which was used to calculate the end-point carbon content, the BOF end-point carbon prediction is divided into three stages in this paper, such as static prediction, dynamic prediction, and intelligent prediction [13-16].

\subsection{Static prediction}

During the whole BOF steelmaking process, operators are usually assisted by a computer-based guidance system, which proposes process parameters and operator actions based on calculations of mass and energy balance and thermodynamic calculations. The static end-point carbon
Target Composition and temperature of end-point liquid steel
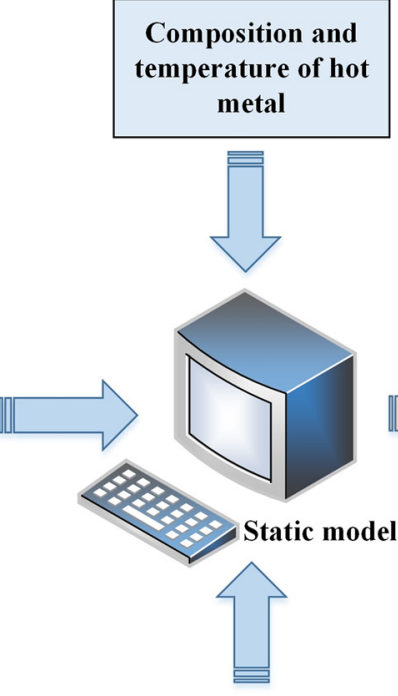

Composition of scrap
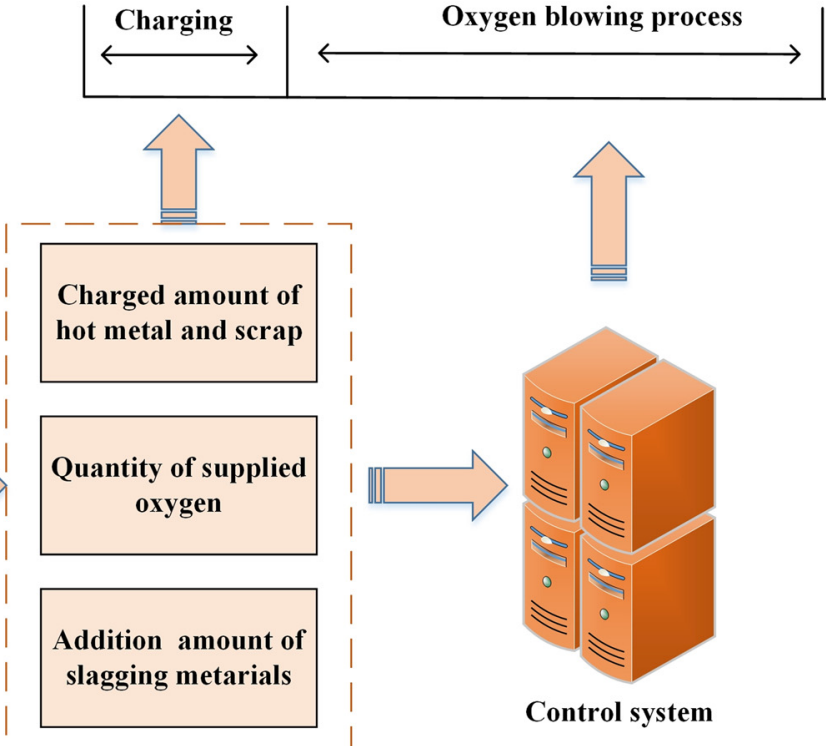

Figure 2: Static end-point carbon prediction for BOF steelmaking. 
prediction for BOF steelmaking mainly relies on the mathematical model established based on mass and heat balance, which can calculate the end-point carbon content in molten steel based on the initial amount (such as charged hot metal and scrap, composition and temperature of hot metal) [17-20]. Figure 2 shows the schematic of static end-point carbon prediction for BOF steelmaking. As can be seen from Figure 2, the key point of static end-point carbon prediction is the reasonable establishment of mathematical mode and acquisition of initial amount data. Compared with the randomness and uncertainty of end-point carbon prediction based on the experience and skill of the operators, the static end-point carbon prediction could perform a quantitative calculation of blown oxygen and end-point carbon content, which would improve the prediction accuracy of BOF end-point carbon. The commonly used mathematical models for static end-point carbon prediction mainly include theoretical model [21-24] and statistical model [25-31].

\subsubsection{Theoretical model}

The theoretical model could calculate the amount of blown oxygen and end-point carbon content based on the calculations of mass and heat balance during the BOF steelmaking process [21-23]. Wang et al. [24] established a theoretical model (oxygen balance model showed as equation (1)) for prediction of the oxygen blowing quantity required in the BOF steelmaking process, which was depicted in Figure 3, but the hit rate of this model was only $62.22 \%$ when the relative errors of the model were within $3 \%$. Due to the complex interaction between various influential factors in the BOF steelmaking process, the calculation of mass and heat balance is usually completed with empirical values and inaccurate; hence, the theoretical model shows a

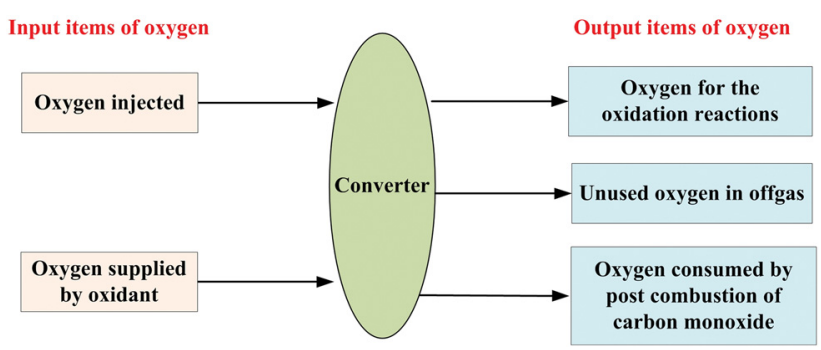

Figure 3: Oxygen balance of the BOF steelmaking process. Adapted from ref. [24]. relatively poor performance on $\mathrm{BOF}$ end-point carbon prediction.

$$
V_{\text {balance, } \mathrm{O}_{2}}=\sum_{i} m_{i} \cdot c_{i}+V_{\text {gas }, \mathrm{O}_{2}}+V_{\mathrm{CO}, \mathrm{O}_{2}}-V_{\text {sinterore, } \mathrm{O}_{2}} \text {, }
$$

where $V_{\text {balance, } \mathrm{O}_{2}}$ is the predicted oxygen blowing quantity, $\mathrm{Nm}^{3} ; m_{i}$ is the amount of oxidized element $i, \mathrm{~kg} ; c_{i}$ is oxygen consumed per unit mass of oxidized element $i, \mathrm{Nm}^{3} \mathrm{~kg}^{-1} ; V_{\mathrm{gas}, \mathrm{O}_{2}}$ is the amount of unused oxygen in the off-gas, $\mathrm{Nm}^{3} ; V_{\mathrm{CO}, \mathrm{O}_{2}}$ is the oxygen quantity consumed by post-combustion of carbon monoxide in the furnace hearth, $\mathrm{Nm}^{3}$; and $V_{\text {sin }}$ terore, $\mathrm{O}_{2}$ is the quantity of oxygen provided by the sinter ore, $\mathrm{Nm}^{3}$.

\subsubsection{Statistical model}

The statistical model only concerns the relation between input variables and output variables using statistical analysis of collected data without considering the chemical reaction mechanism in a molten bath, which is depicted in equation (2) [25]. As a kind of statistical model, the neural network combined with different algorithms is widely applied to the end-point prediction for BOF steelmaking in recent years [26-28], and Figure 4 presents the BP neural network for BOF end-point carbon prediction. Compared with the theoretical model, the neural network is specialized in analyzing random deviation and eliminating the influence of random factors and it could provide a more reliable reference for BOF end-point carbon prediction.

$$
X=F(W, S, T, \tau, Z),
$$

where $F$ is a linear or nonlinear function, $W$ is the charged weight of hot metal and scrap, $S$ are the target values of end-point composition in liquid steel, $T$ is the initial temperature of hot metal, $\tau$ is the oxygen blowing time, and $Z$ are other important influential factors (such as top lance height and oxygen pressure).

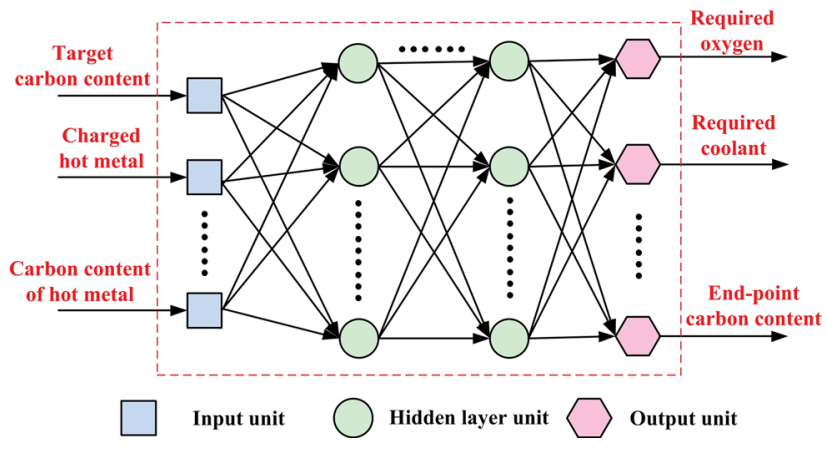

Figure 4: BP neural network for BOF end-point carbon prediction. 
However, the theoretical and statistical models described in the above section are only built on consideration of initial conditions and static process data (a small dataset without time-series feature could not represent the actual production), making static endpoint carbon prediction models unsuitable for actual production; the prediction accuracy is limited. A particular challenge of static end-point carbon prediction is the reasonable establishment of prediction models based on a large production dataset that has a timeseries feature. Based on the above challenge, the dynamic end-point carbon prediction is rapidly developed based on static prediction.

\subsection{Dynamic prediction}

Differed from the static control, the dynamic end-point carbon prediction could predict the end-point carbon content in liquid steel and fulfill on-line adjustment of operating parameters with the calculation of dynamic models established on the time-series data (lance movements, carbon monoxide $\mathrm{CO}$ and carbon dioxide $\mathrm{CO}_{2}$ levels of the off-gas, spectral features of the flame) collected by monitoring devices [32-34], which was depicted in Figure 5. Currently, the sub-lance system [35-42], offgas analysis system [43-50], and flame spectrometric analysis system [51-56] are the primary methods that are applied to dynamic end-point carbon prediction for BOF steelmaking.

\subsubsection{Sub-lance system}

The dynamic end-point prediction with the sub-lance system would directly measure the carbon content of liquid steel at a later stage of the blowing process, build the on-line prediction model (e.g. equation (3)), and dynamically predict

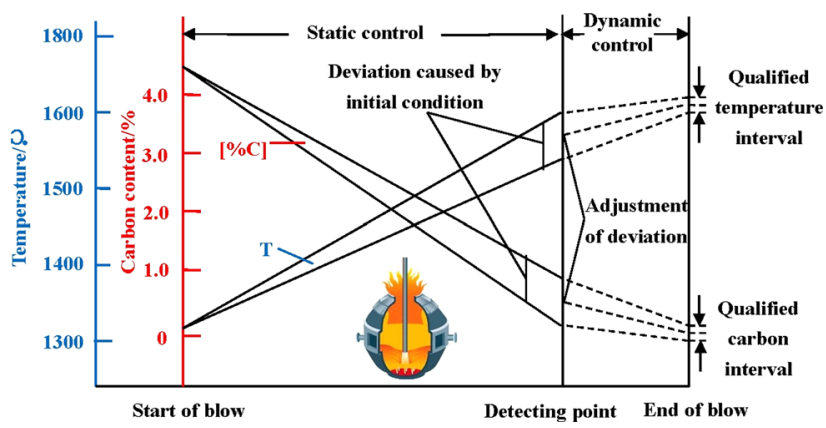

Figure 5: Dynamic end-point carbon prediction for BOF steelmaking. the carbon content with different blowing time [35-37], which was presented in Figure 6.

$$
-\frac{\mathrm{d} C}{\mathrm{~d} \tau}=k\left(C-C_{s}\right),
$$

where $k$ is the reaction rate constant for BOF decarburization, $\mathrm{s}^{-1}, C$ is the carbon content in liquid steel, $\%, C_{\mathrm{s}}$ is measured carbon content with sub-lance system, \%, and $\tau$ is the oxygen blowing time, s.

With the application of a sub-lance system, the influence of initial deviation on charged materials could be alleviated, and the end-point carbon prediction for BOF steelmaking is more efficient and precise (some Japanese steel plants achieved a carbon predictive accuracy of more than $90 \%$ with an error tolerance of $\pm 0.02 \%$ ) compared with static prediction [38-40].

\subsubsection{Off-gas analysis system}

Figure 7 presents the schematic diagram of the off-gas analysis system at ArcelorMittal Dofasco [43]. Through monitoring the off-gas information $\left(\mathrm{CO}\right.$ and $\mathrm{CO}_{2}$ content change during oxygen blowing), the carbon content of molten steel could be dynamically inferred with a mathematical model (e.g., equation (4)) based on offgas information, and the end-point carbon content could be predicted and controlled with the feedback of calculation results [44-47].

$$
\begin{aligned}
-\frac{\mathrm{d} C}{\mathrm{~d} \tau}= & \frac{12 \times 100}{22.4 \times 100 \times 1,000 \cdot W_{\text {steel }}} \\
& \cdot\left[Q_{\mathrm{gas}}\left(\omega_{\mathrm{CO}}+\omega_{\mathrm{CO}_{2}}\right)\right],
\end{aligned}
$$

where $C$ is the carbon content in liquid steel, $\tau$ is the oxygen blowing time, $Q_{\text {gas }}$ is the off-gas flowrate, $W_{\text {steel }}$ is the weight of molten steel, $\omega_{\mathrm{CO}}$ is CO content of the offgas, and $\omega_{\mathrm{CO}_{2}}$ is $\mathrm{CO}_{2}$ content of the off-gas.

As an indirect estimation method, the accuracy of collected data (such as off-gas content and flowrate) and the respond time of mathematical model would greatly affect the prediction accuracy of BOF end-point carbon [48-50]. Therefore, the off-gas analysis system is usually used together with sub-lance system to control the BOF end-point carbon with required accuracy in many steel plants.

\subsubsection{Flame spectrometric analysis system}

Spectral features of the flame at the BOF vessel mouth which are related to the carbon content of molten steel 


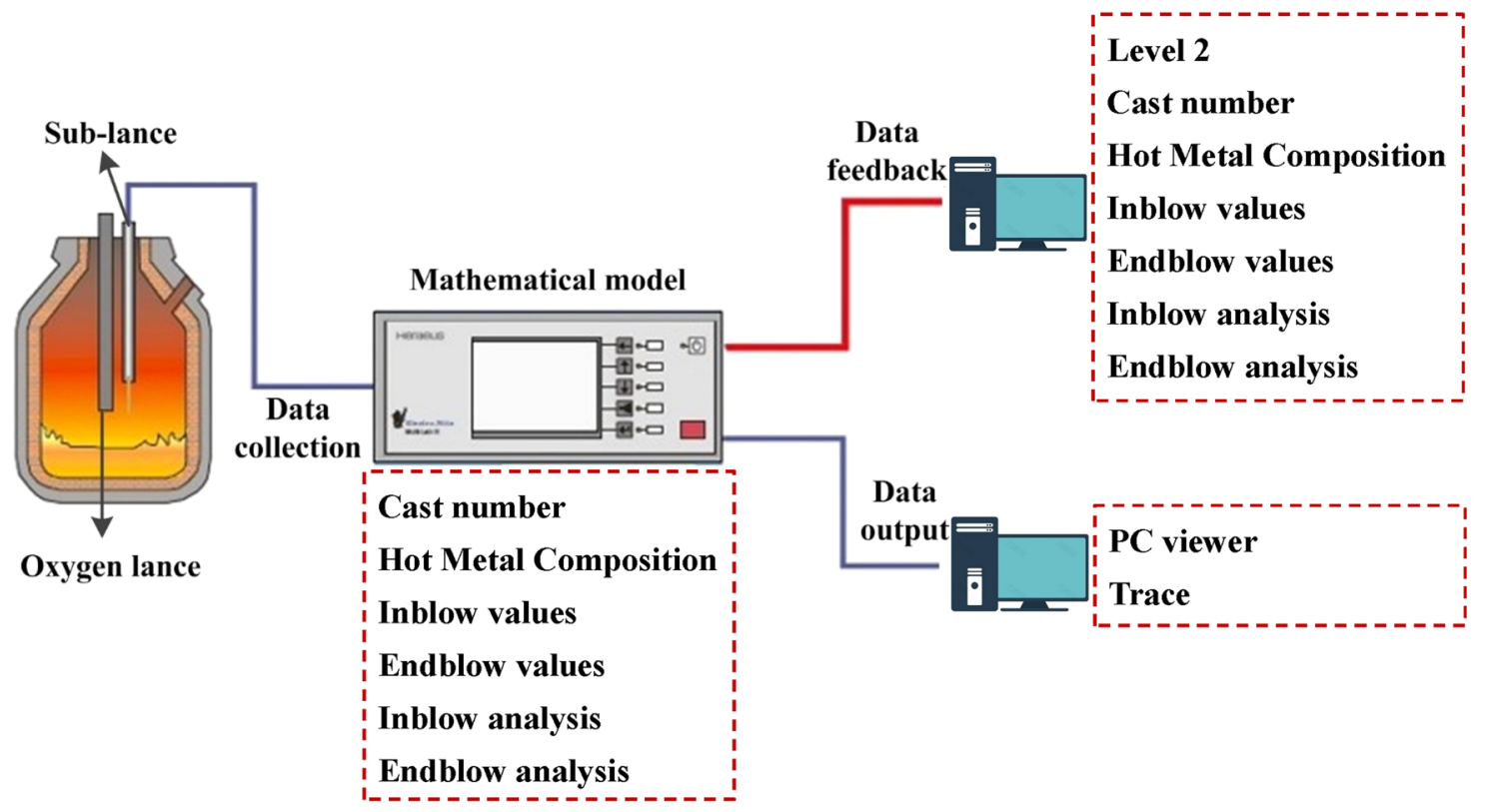

Figure 6: Dynamic end-point carbon prediction with the sub-lance system. Adapted from ref. [37].

would change during the BOF steelmaking process. Based on the spectral characteristics of the flame radiation information, the flame spectrometric analysis system is developed to predict end-point carbon content [51-53]. Just as Figure 8 showed, through analyzing the relation between flame spectrum of different blowing time and converter bath status, the on-line prediction of carbon content of liquid steel could be completed [54-56]. Optical sensors were used to dynamically predict the carbon content of low carbon heats (the target end-point carbon content was lower than 0.06\%) in BOF steelmaking at Bethlehem Steel Corporation [51], which had resulted in a significant improvement.

Although the dynamic end-point carbon prediction could give a significant prediction improvement when compared with the static prediction, the collection of a real, fullsized, and rich dataset that could represent the overall

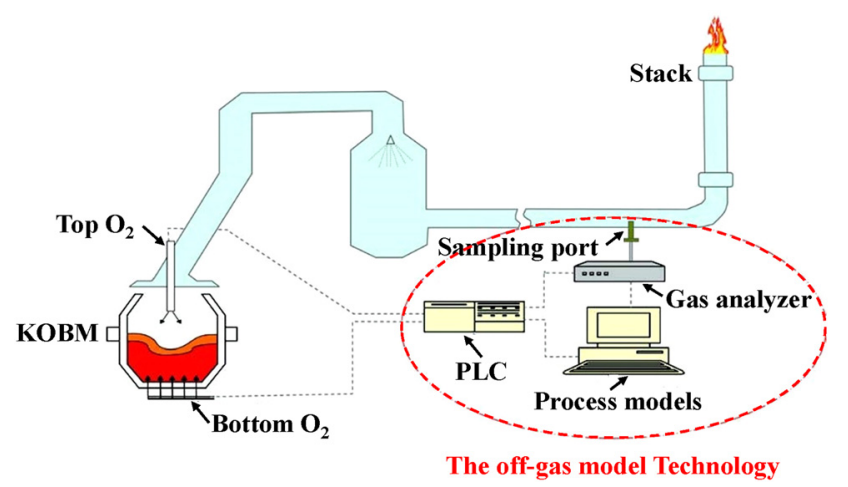

Figure 7: Off-gas analysis system at Dofasco. Adapted from ref. [43]. behavior of entire steelmaking process, self-learning, and self-adapting of the prediction model are particular challenges of dynamic end-point carbon prediction. Hence, the intelligent end-point carbon prediction is built based on dynamic end-point carbon prediction.

\subsection{Intelligent prediction}

With the development of data collection and intelligent models, intelligent end-point carbon prediction for BOF
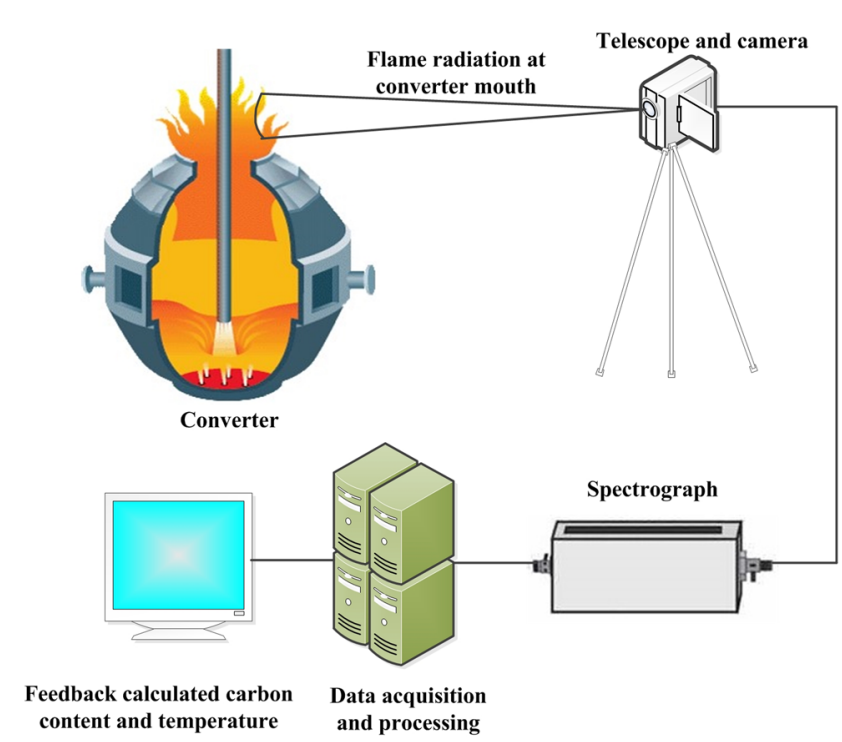

Figure 8: Schematic of the flame spectrometric analysis system. 


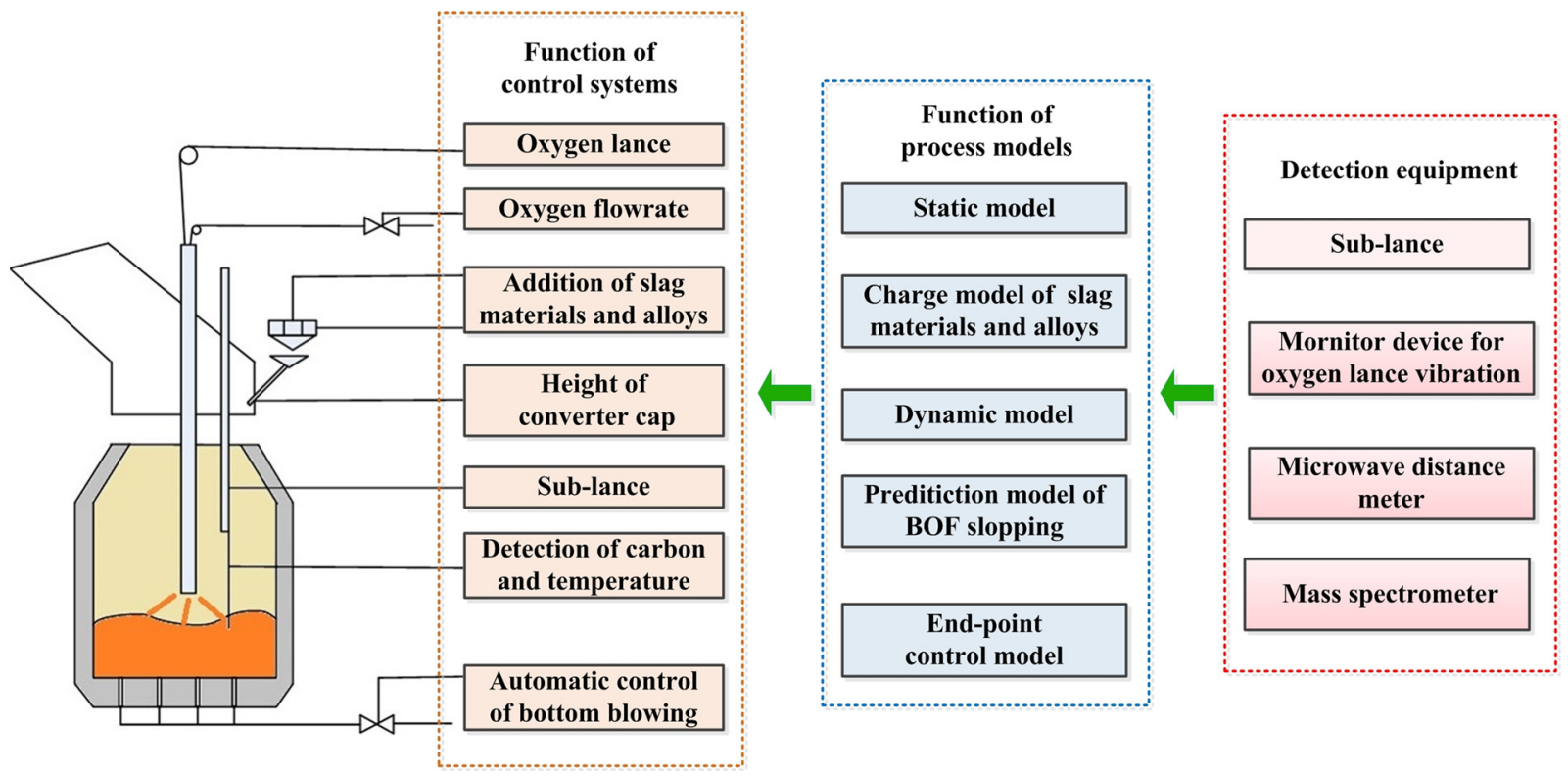

Figure 9: Frame of automatic BOF steelmaking system at Nippon Steel Corporation.

steelmaking become available, which is established on the basis of full-sized and rich dataset with different features and has strong ability of self-learning to improve

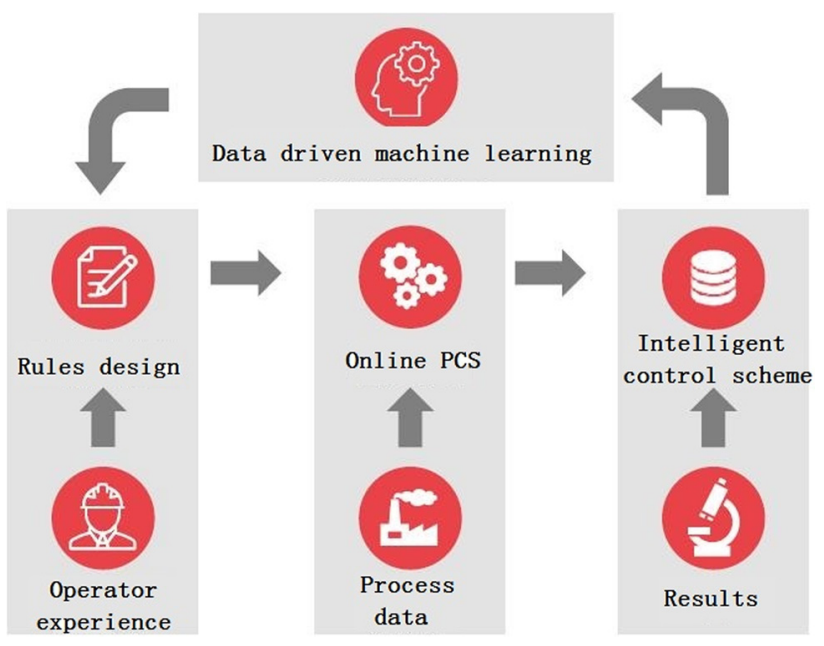

Figure 10: Establishment of an intelligent model. prediction accuracy [57-60]. Figure 9 presents the frame of automatic BOF steelmaking system at Nippon Steel Corporation [57]. Besides the sub-lance system, automatic BOF steelmaking system mainly adopt other techniques [61-63]: (1) online slag detection during oxygen blowing provide the guidance for slagging operation, (2) off-gas analysis system dynamically estimate the carbon content and temperature of liquid steel during blowing process, and (3) intelligent models with strong ability of self-learning and self-adapting, which is shown in Figure 10. With application of above techniques, the intelligent endpoint carbon prediction for BOF steelmaking could be automatically and efficiently implemented with computer rather than manual operation, and the prediction accuracy of end-point carbon content is greatly improved [64]. With the practical application of intelligent endpoint prediction at No. 2 BOF shop in Kashima Steel Works, the reblow ratio was decreased from $14 \%$ to $1 \%$, and the tap-to-tap time was reduced from 37 to $29 \mathrm{~min}$, which greatly improved the efficiency of the BOF steelmaking process [2].

Table 1: Comparison of different end-point carbon prediction

\begin{tabular}{llll}
\hline Prediction method & Detection equipment and model & Control range & Hit rate \\
\hline Static prediction & Theoretical model and statistical model & {$[\mathrm{C}] \pm 0.02 \%$} & $\leq 70 \%$ \\
Dynamic prediction & Sub-lance, off-gas analysis, and flame spectrometric analysis & {$[\mathrm{C}] \pm 0.02 \%$} & $80-90 \%$ \\
& system with a dynamic model & {$[\mathrm{C}] \pm 0.02 \%$} & $\geq 90 \%$ \\
\hline
\end{tabular}




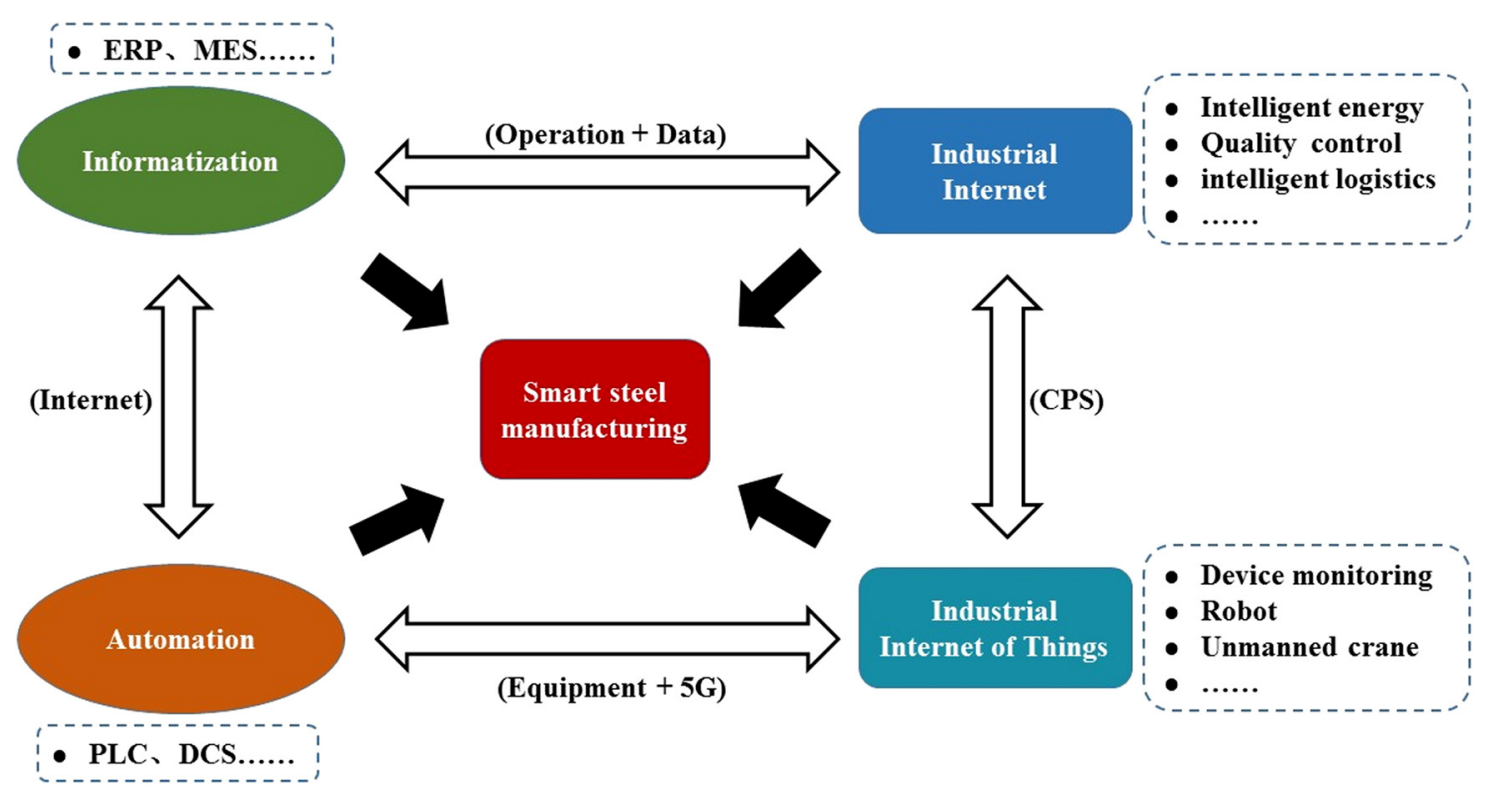

Figure 11: Construction of smart steel manufacturing.

Table 1 shows the comparison of static, dynamic, and intelligent end-point carbon prediction for BOF steelmaking. There is no doubt that intelligent prediction would greatly improve the prediction accuracy of end-point carbon content and promote the BOF steelmaking process.

Recently, more and more auto-detection techniques are developed and applied to the end-point carbon control for BOF steelmaking, such as robotic sampling and temperature measuring system [65], wireless composition measuring system [66], and so on. Meanwhile, Industrial Internet of Things (IIoT) is developed rapidly along with the fifth generation mobile communication technology (5G) and big data analytics [67-70], and it is gradually applied to smart steel manufacturing (just as Figure 11 showed). Therefore, the intelligent end-point carbon prediction for BOF steelmaking would gain more attention in future.

From the industrial implementation point of view, the intelligent end-point carbon prediction model with high accuracy could be installed on existing process system, continuously predicting the process carbon content and providing the guidance for operators based on the actual events and planned events during the BOF steelmaking process.

\section{Conclusions and outlook}

This paper has presented the significant progress in regard to end-point carbon prediction for BOF steelmak- ing. It can be concluded that dynamic end-point carbon prediction with sub-lance system and off-gas analysis system has gained more industrial application to modern BOF steelmaking process and shows a better performance on the prediction accuracy, when compared with static end-point carbon prediction. However, the off-gas analysis system should overcome the difficulty of accurate and real-time access to off-gas information and usually cooperates with sub-lance system in modern BOF steelmaking.

The emerging of flame spectrometric analysis system, robotic sampling and temperature measuring system, and wireless composition measuring system could provide new approaches to intelligent end-point carbon prediction for BOF steelmaking. With the development of information technology (such as Industrial Internet of Things, the fifth generation mobile communication technology and big data analytics) and new auto-detection techniques, it is envisaged that the intelligent end-point carbon prediction will witness more frequent application to BOF steelmaking and greatly promote the smart steel manufacturing in the coming year. Yet, it is challenging to determine the influencing factors and automate the parameters in real time among full-sized and rich dataset and generalize the model and resolve uncertainty issues that caused by human error, measuring devices, and prediction error.

Acknowledgments: The authors are grateful to the Ministry of Science and Technology of China and Henan Provincial Department of Science and Technology for providing funding under National Key Research and Development 
Program of China (2016YFB0300603) and Provincial Scientific and Technological Project (172102210041) for supporting this research.

Conflict of interest: Authors state no conflict of interest.

\section{References}

[1] Basson, E. Steel Statistical Yearbook 2019, Worldsteel Committee on Economic Studies, Brussels, 2019.

[2] Takawa, T., K. Katayama, and M. Hoteiya. Development of a mathematical model of end point control system for top and bottom blowing process in BOF. Tetsu-to-Hagane, Vol. 73, No. 7, 2009, pp. 836-843.

[3] Cao, L. L., Q. Liu, Z. Wang, and N. Li. Interaction behaviour between top blown jet and molten steel during BOF steelmaking process. Ironmaking \& Steelmaking, Vol. 45, No. 3, 2018, pp. 239-248.

[4] Blanco, C. and M. Diaz. Model of mixed control for carbon and silicon in a steel converter. ISIJ International, Vol. 33, No. 7, 1993, pp. 757-763.

[5] Kato, Y. and H. Okuda. Reaction model for carbon, manganese, and oxygen in bottom blowing with mixed gas in final stage of steel refining in converter. ISIJ International, Vol. 43, No. 11, 2003, pp. 1710-1714.

[6] Bramming, M., B. Bjorkman, and C. Samuelsson. BOF process control and slopping prediction based on multivariate data analysis. Steel Research International, Vol. 87, No. 3, 2016, pp. 301-310.

[7] Zhu, M. Y., W. T. Lou, and W. L. Wang. Research progress of numerical simulation in steelmaking and continuous casting processes. Acta Metallurgica Sinica, Vol. 54, No. 2, 2018, pp. 131-150.

[8] Cao, L., Y. Wang, Q. Liu, and X. M. Feng. Physical and mathematical modeling of multiphase flows in a converter. ISIJ International, Vol. 58, No. 4, 2018, pp. 573-584.

[9] Bae, J., Y. Li, N. Stahl, G. Mathiason, and N. Kojola. Using Machine Learning for Robust Target Prediction in a Basic Oxygen Furnace System. Metallurgical and Materials Transactions B, Vol. 51, No. 4, 2020, pp. $1632-1645$.

[10] Lukyanov, A. V., A. V. Protasov, B. A. Sivak, and A. P. Shchegolev. Making BOF steelmaking more efficient based on the experience of the cherepovets metallurgical combine. Metallurgist, Vol. 60, No. 3, 2016, pp. 248-255.

[11] Hanafy, A. R. and M. F. Sakr. Database-aided tuning for the BOF static model. IFAC Proceedings Volumes, Vol. 20, No. 9 , 1986, pp. 537-542.

[12] Liu, H., B. Wang, and X. Xiong. Basic oxygen furnace steelmaking end-point prediction based on computer vision and general regression neural network. Optik, Vol. 125, No. 18, 2014, pp. 5241-5248.

[13] Li, G. H. and Q. Liu. Present statues and prospect of BOF steelmaking process control. Journal of Iron and Steel Research, Vol. 25, No. 1, 2013, pp. 1-4.
[14] Xu, G., H. B. Lei, J. H. Li, Y. P. Ye, and J. Xue. End-point control techniques for converter steel-making. Steelmaking, Vol. 27, No. 1, 2011, pp. 66-70.

[15] Feng, S. C., Y. H. Wang, and R. F. Ding. Application statues of end-point control technologies in converter steelmaking. Metallurgical Industry Automation, Vol. 40, No. 2, 2016, pp. 1-6.

[16] Takawa, T., K. Katayama, and M. Hoteiya. Mathematical model of end point control for the top and bottom blowing process in BOF. Transactions ISIJ, Vol. 27, 1987, pp. 951-958.

[17] Li, G. H., B. Wang, Q. Liu, X. Z. Tian, R. Zhu, L. N. Hu, and et al. A process model for BOF process based on bath mixing degree. International Journal of Minerals, Metallurgy and Materials, Vol. 17, No. 6, 2010, pp. 715-722.

[18] Tang, B., X. M. Wang, Z. S. Zou, and A. B. Yu. Static model for converter steelmaking with limestone. Journal of Northeastern University (Natural Science), Vol. 35, No. 4, 2014, pp. 534-538.

[19] Huang, J. X. and N. D. Jin. Static control predictive model for converter refining end-point. Steelmaking, Vol. 22, No. 1, 2006, pp. 45-48.

[20] Slatosky, W. J. End-point temperature control in LD Steelmaking. JOM, Vol. 12, No. 3, 1960, pp. 226-230.

[21] He, P., L. Liu, and J. X. Zhao. Improvement and application of comprehensive and intelligent models for static control of steelmaking in converter, Research on Iron \& Steel, Vol. 40, No. 6, 2012, pp. 22-26.

[22] Ding, R. and L. Liu. Artificial intelligence static control model in converter steelmaking, Iron and Steel, Vol. 32, No. 1, 1997, pp. 22-26.

[23] Chen, J. D., C. J. Zhang, and J. H. Feng. Static mechanics model in loading converter and energy saving, Journal of Hebei Institute of Technology, Vol. 29, No. 1, 2007, pp. 32-35.

[24] Wang, Z., Q. Liu, F. Xie, B. Wang, B. Wang, and X. C. Lu. Model for prediction of oxygen required in BOF steelmaking. Ironmaking \& Steelmaking, Vol. 39, No. 3, 2012, pp. 228-233.

[25] Pal, J., S. Singh, and A. K. Ghose. A mathematical model for end point control of basic oxygen steel making furnace, Journal of Metallurgy and Materials Science, Vol. 44, No. 1, 2002, pp. 39-49.

[26] Cox, I. J., R. W. Lewis, R. S. Ransing, H. Laszczewski, and G. Berni. Application of neural computing in basic oxygen steelmaking. Journal of Materials Processing Technology, Vol. 120, No. 1, 2002, pp. 310-315.

[27] He, F. and L. Zhang. Prediction model of end-point phosphorus content in BOF steelmaking process based on PCA and BP neural network. Journal of Process Control, Vol. 66, 2018, pp. 51-58.

[28] Cunha, A. P., T. A. Pacianotto, and A. M. Fileti. Steelmaking process: neural models improve end-point predictions. Computer Aided Chemical Engineering, Vol. 18, No. 4, 2004, pp. 631-636.

[29] Wang, Z., F. Xie, B. Wang, Q. Liu, X. C. Lu, L. N. Hu, et al. The control and prediction of end-point phosphorus content during BOF steelmaking process. Steel Research International, Vol. 85, No. 4, 2014, pp. 599-606.

[30] Wang, Z., J. Chang, Q. Ju, F. M. Xie, B. Wang, H. W. Li, et al. Prediction model of end-point manganese content for BOF steelmaking process. ISIJ International, Vol. 52, No. 9, 2012, pp. 1585-1590. 
[31] Laha, D., Y. Ren, and P. N. Suganthan. Modeling of steelmaking process with effective machine learning techniques. Expert Systems with Applications, Vol. 42, No. 10, 2015, pp. 4687-4696.

[32] Wauters, M., V. Tusset, J. Knevels, R. Meilland, T. Björk, and A. Bengston. New sampling and analysis method for dynamic end-point control at BOF process. Metallurgical Analysis, Vol. 26, 2006, pp. 8-15.

[33] Meilland, R., M. Wauters, J. Knevels, and A. Bengston. Dynamic end-point control in BOF through a fast and simultaneous determination of the steel/slag composition. Revue De Métallurgie, Vol. 103, No. 9, 2006, pp. 374-380.

[34] Maiolo, J. and D. Zuliani. BOF end-point prediction. Metal Producing and Processing, Vol. 46, No. 6, 2008, pp. 15-18.

[35] Hubbeling, P. D. and G. A. Oostermeijer. Sublance and dynamic control in converter steelmaking. Iron and Steel, Vol. 42, No. 4, 2007, pp. 83-86.

[36] Gutte, H., T. Schulz, G. Neuhof, and D. Janke. Process control in the oxygen steel production. Acta Metallurgica Sinica, Vol. 13, No. 6, 2000, pp. 1101-1112.

[37] Spanjers, M. and W. Glitscher. Sublance-based on-line slag control in BOF steelmaking. AISTech 2005 Proceedings, May 2005, Charlotte, USA, pp. 325-331.

[38] Vortrefflich, W. and J. Vries. Maximizing BOF production capacity and producing cost efficient by using sublance based process control. Iron \& Steel Review, Vol. 10, 2010, pp. 94-100.

[39] lida, Y., K. Emoto, M. Ogawa, Y. Masuda, M. Onishi, and H. Yamada. Fully automatic blowing technique for basic oxygen steelmaking furnace. Transactions of the Iron and Steel Institute of Japan, Vol. 24, No. 7, 1984, pp. 540-546.

[40] Robertson, K. J., S. R. Balajee, J. M. Shearer, and J. E. Bradley. The sublance dynamic control operation and its effect on the performance of the Inland Steel Company's No. 4 BOF shop. Proceedings of Steelmaking Conference, 1989, Iron and Steel Society, IL, Chicago, USA, pp. 159-166.

[41] Yue, F., Y. Bao, and H. Cui. Sub-lance control-based predication model for BOF end-point. Steelmaking, Vol. 25, No. 1, 2009, pp. 38-40.

[42] Zuo, K., J. Zou, and X. Sun. Sub-lance mensuration and composition prediction in BOF steelmaking. Steelmaking, Vol. 25, No. 2, 2009, pp. 59-61.

[43] Sun, S., D. Liao, N. Pyke, K. Boylan, and N. Pyke. Development of an offgas/model technology to replace sublance operation for KOBM endpoint carbon control at ArcelorMittal dofasco. Iron \& Steel Technology, Vol. 5, No. 11, 2008, pp. 36-42.

[44] Liao, D., S. Sun, and K. Boylan. Systematic KOBM process control based on off gas information. AISTech 2013 Proceedings, 2013, Association for Iron \& Steel Technology, Pittsburgh, USA, pp. 839-850.

[45] Fukumi, J., C. Taki, and T. Hatanaka. Development of refining control system in combined blowing converter based on exhaust gas information. The Iron and Steel Institute of Japan, Vol. 76, No. 11, 1990, pp. 192-199.

[46] Takawa, T., M. Sato, and T. Okada. Development of automatic blowing technique in BOF based on a mathematical model. The Iron and Steel Institute of Japan, Vol. 74, No. 4, 1988, pp. 664-671.
[47] Liu, K., L. Liu, P. He, and W. Liu. A new algorithm of endpoint carbon content of BOF based on of off-gas analysis. Steelmaking, Vol. 25, No. 1, 2009, pp. 33-37.

[48] Wu, M. and F. Wu. Application of using dynamic control with offgas analysis for making medium-high carbon steel. Iron and Steel, Vol. 42, No. 12, 2007, pp. 38-41.

[49] Zhang, G., X. Wan, D. Lin, F. Peng, and Z. S. Zou. Carbon content and temperature variation of bath based on exhaust gas analysis. Journal of Iron and Steel Research, Vol. 18, No. 11, 2006, pp. 56-59.

[50] He, P., L. Liu, K. Liu, and K. Zhao. Critical carbon content in BOF blowing process with gas analysis. Journal of University of Science and Technology Beijing, Vol. 31, No. 2, 2009, pp. 156-162.

[51] Sharan, A. Light sensors for BOF carbon control in low carbon heat. Steelmaking Conference Proceedings, ISS-AIME, Toronto, Canada, 1998, pp. 337-345.

[52] Cardin, M., J. MacGregor, I. Miletic, and M. Bruwer. Image-based endpoint carbon prediction for a basic oxygen furnace. Iron \& Steel Technology, Vol. 8, No. 11, 2011, pp. 79-85.

[53] Zhou, M., Q. Zhao, and Y. Chen. Endpoint prediction of BOF by flame spectrum and furnace mouth image based on fuzzy support vector machine. Optik, Vol. 178, 2019, pp. 575-581.

[54] Shao, Y., Y. Chen, Q. Zhao, M. C. Zhou, and X. Y. Dou. Endpoint temperature prediction of the basic oxygen furnace based on the flame temperature measurement at the converter mouth. Spectroscopy and Spectral Analysis, Vol. 35, No. 11, 2015, pp. 3023-3027.

[55] Jiang, F., H. Liu, B. Wang, and X. F. Sun. Basic oxygen furnace blowing endpoint judgment method based on flame image convolution neural network. Computer Engineering, Vol. 42, No. 10, 2016, pp. 277-282.

[56] You, J., S. Wang, X. Li, and Y. P. Han. Estimate blowing final point by analyzing texture features of top-blowing BOF vessel mouth flame. Journal of University of Science and Technology Beijing, Vol. 22, No. 6, 2000, pp. 524-528.

[57] Kanemot, M., H. Yamane, T. Yoshida, and H. Tottori. An application of expert system to LD converter process. ISIJ International, Vol. 30, No. 2, 1990, pp. 128-135.

[58] Notman, G., Developments in BOS process control at British steel. Steel Times, Vol. 15, No. 7, 1991, pp. 360-361.

[59] Makino, T., S. Omiya, and N. Kitagawa. Automatic operation of converters at Mizushima works. Steelmaking Conference Proceedings, 1994, ISS-AIME, Warrendale, USA, pp. 67-71.

[60] Cushin, G., L. Cates, and R. Berret. Q-BOP automation at Geneva steel. Iron and Steel Engineer, Vol. 71, No. 7, 1994, pp. 21-24.

[61] Carayannis, G., Artificial intelligence and expert systems in the steel industry. JOM, Vol. 45, No. 10, 1993, pp. 43-51.

[62] Saito, T., K. Ebato, and I. Tsubone. Estimation technique of blow-end compositions. Tetsu to Hagane, Vol. 76, No. 11, 1990, pp. 208-213.

[63] Iwamura, K., New endpoint control system with auto-parameter-tuning in BOF. Steelmaking Conference Proceedings, ISS-AIME, Nashville, USA, 1995, pp. 715-719.

[64] Wang, X., Outlook on progress of steelmaking technology in transition period of Chinese steel industry. Steelmaking, Vol. 35, No. 1, 2019, pp. 1-11. 
[65] Su, Q. and Z. Ma. Introduction of robot for steelmaking sample inspection automation. Gansu Metallurgy, Vol. 40, No. 5, 2018, pp. 105-107.

[66] Janu, D., R. Rote, and T. Junker. Wireless technology: a revolution in temperature, oxygen and carbon measurements in molten metal. Iron \& Steel Technology, Vol. 8, No. 11, 2011, pp. 37-45.

[67] Zhang, J., Y. Zhou, R. Xu, G. Wang, and K. Jiao. Model of internet + CPPS for smart steel factory. Iron and Steel, Vol. 51, No. 4, 2016, pp. 1-7.
[68] Liu, W. Z., Current situation and thinking of intelligent manufacturing in China's iron and steel industry. China Metallurgy, Vol. 30, No. 6, 2020, pp. 1-7.

[69] Chen, L. P. and Y. Liu. Design and practice of 3D digital factory in iron and steel enterprise. Metallurgical Industry Automation, Vol. 44, No. 4, 2020, pp. 27-30.

[70] Buchi, G., M. Cugno, and R. Castagnoli. Smart factory performance and Industry 4.0. Technological Forecasting \& Social Change, Vol. 150, 2020, pp. 1-10. 